\title{
Scanning Electron Microscope (SEM) Coupled with Energy Dispersive X-ray Spectroscopy (EDS) - A Potential Analytical Tool for Physico-chemical Characterization of API in Complex Drug Formulations
}

Mehulkumar Patel, Soumyarwit Manna, Anh Vo, Xiaoming Xu, Denise Conti, Stephanie Choi, Darby Kozak and Jiwen Zheng

US Food and Drug Administration, Silver Spring, Maryland, United States

* Corresponding author: Jiwen.zheng@fda.hhs.gov

\section{Introduction}

Comprehensive physicochemical characterization (e.g., morphology and composition) of the active pharmaceutical ingredient (API) in complex drug formulations provides critical information to support bioequivalence of complex generic drug formulations to the reference listed drug (RLD) product. However, such characterization is rather challenging due to many factors, such as complex nature of formulation (e.g. solution vs. suspension), unique physicochemical properties of API (e.g., solubility, stability) as well as interference from the other excipients (e.g., similar chemical composition/properties and morphology as API). In this work, through two case studies, Nasonex ${ }^{\circledR}$ (mometasone furoate monohydrate nasal spray suspension) and Azopt $^{\circledR}$ (brinzolamide ophthalmic suspension), we demonstrated that SEM coupled with EDS can be a valuable tool for morphological and compositional characterization of the API in complex drug formulations.

\section{Methods}

For Nasonex ${ }^{\circledR}$, samples were shaken for 5 seconds and sprayed twice into $1.5 \mathrm{~mL}$ Eppendorf tube and then diluted 4 times with deionized water. After that, $100 \mu \mathrm{L}$ of sample was deposited on an aluminum stub or $0.2 \mu \mathrm{m}$ polycarbonate (PC) filter paper and then air-dried overnight in fume hood. For Azopt ${ }^{\circledR}, 1$ $\mathrm{mL}$ of suspension was first centrifuged at $15,000 \mathrm{~g}$ for 15 minutes and supernatant was collected. A fresh aliquot of $\mathrm{Azopt}^{\circledR}$ suspension was diluted 10 times using the supernatant and deposited on $0.05 \mu \mathrm{m}$ PC filter paper via vacuum filtration and air-dried overnight in fume hood. After drying, both samples were sputter coated with gold ( $5 \mathrm{~nm}$ thick) prior to SEM-EDS analysis using TESCAN Mira 3 (Tescan USA Inc., Warrendale, PA, USA) equipped with an Oxford X-Max 80 EDS detector (Oxford Instruments, Abingdon, UK).

\section{Results}

Both EDS mapping and point-shoot analysis of Nasonex ${ }^{\circledR}$ and Azopt ${ }^{\circledR}$ products shows that the API's in Nasonex ${ }^{\circledR}$ and Azopt ${ }^{\circledR}$ can be distinguished from other excipients based on the detection of specific characteristic element, such as Chlorine $(\mathrm{Cl})$ in mometasone furoate (Figure 1) and Sulfur $(\mathrm{S})$ in brinzolamide. For Nasonex ${ }^{\circledR}$ product, SEM image analysis (Figure 1) showed the mometasone furoate particles, confirmed based on presence of $\mathrm{Cl}$ element, have an aspect ratio approximately 2:1 which is consistent with the result from Morphologically-Directed Raman Spectroscopy (MDRS) analysis.[1] While for Azopt ${ }^{\circledR}$ product, the brinzolamide particles, detected based on presence of $S$ element, have a linear dimensions ranging from 1 to $5 \mu \mathrm{m}$, which is complementing to the value we obtained from laser diffraction analysis $(\mathrm{D} 50=2.5 \mu \mathrm{m})$. 


\section{Conclusions}

Based on EDS spectral detection and subsequent SEM image analysis of two complex drug formulations (Nasonex ${ }^{\circledR}$ nasal spray suspension and Azopt ${ }^{\circledR}$ ophthalmic suspension), SEM-EDS appear to be an analytical tool capable of simultaneous morphological characterization (quantitative) and chemical identification (qualitative) of API in these complex drug formulations. This work reveals SEM-EDS as an additional option for API characterization which may provide relevant information to support bioequivalence and drug product quality.

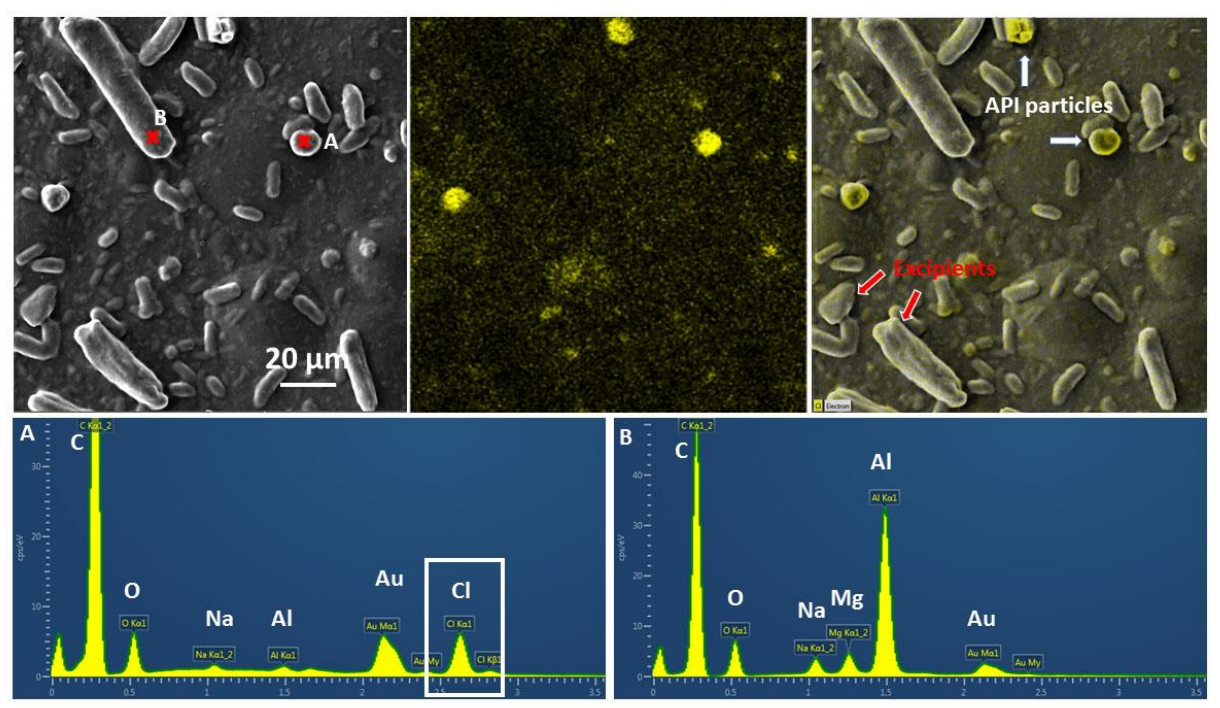

Figure 1. SEM and EDS analysis of Nasonex® nasal spray (suspension of mometasone furoate monohydrate). Top left is a SEM image, in middle is "Cl" element EDS mapping image and right is overlay image of SEM and "Cl" element mapping of Nasonex ${ }^{\circledR}$ nasal sprays. Mometasone furoate monohydrate particles and excipient particles were shown in white and red arrow respectively. Bottom left is point-shoot EDS spectrum of Momentasone furoate monohydrate API particles and bottom right is point-shoot EDS spectrum of other inactive excipients.

\section{Acknowledgements}

This project was supported in part by an appointment to the Research Participation Program at Center for Drug Evaluation and Research administered by the Oak Ridge Institute for Science and Education through an agreement between the U.S. Department of Energy and FDA. The authors would like to acknowledge FDA Advanced Characterization Facility (ACF), CDRH/OSEL/DBCMS for instrument use.

\section{Disclaimer}

This article reflects the views of the authors and should not be construed to represent FDA's views or policies.

\section{References}

[1] Liu, Q., et al., Scientific Considerations for the Review and Approval of First Generic Mometasone Furoate Nasal Suspension Spray in the United States from the Bioequivalence Perspective. The AAPS journal, 21(2), p.14. 